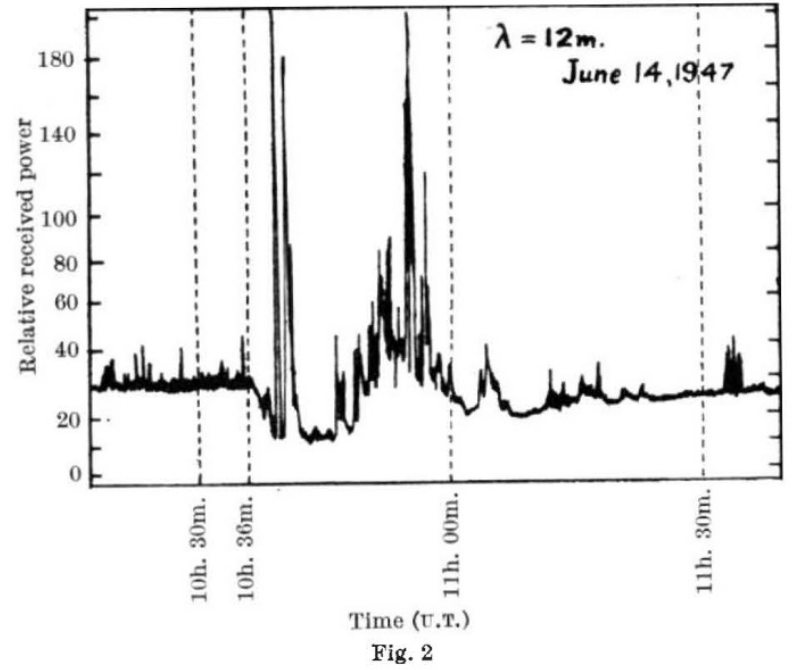

It is thus evidont that radio noiso observations can be of special value in indicating $D$-layer ionization by the absorption effects on the galactic radio waves reaching tho earth when solar radio emissions are small, or when the absorption precodes a solar radio burst. The time lag in the latter case might be interpreted as follows : the ultra-violet radiations giving rise to the enhanced $D$-layer ionization might be due to a solar disturbance travelling outwards from the sun, the electron density in the solar envelope being too great (see Saha ${ }^{3}$, Martyn ${ }^{4}$ ) to allow radio-frequency waves to escape until the disturbance has reached the corona.

We wish to thank Sir Edward Appleton and Mr. $H$. W. Newton for their helpful suggestions and discussion. We are indebted to the Astronomer Royal for the information on magnetic crochets, to Cable and Wireless, Ltd., for the particulars of the radio fade-outs, and to the Chief Sciontist, Ministry of Supply, for permission to publish this communication.

J. S. HEY

S. J. PARSONS

J. W. Phinlips

Ministry of Supply, O.R.G. (W. \& E.),

Broadoaks, West Byfleet,

Surrey.

Aug. 20.

${ }^{1}$ Appleton and Hey, Phil. Mag., 37, 73 (1946).

- Jansky, Proc. Inst. Rad. Enı., 20, 1920 (1932); 21, 1887 (1933); 23, 1158 (1935): 25, 1517 (1937).

${ }^{3}$ Saha, Nature, 158, 599 (1946).

- Martyn, Nature, 159, 26 (1947).

\section{Radio Echoes from the Aurora Borealis}

DurING the night of August 15-16, 1947, radio echoes were obtained apparently arising from a luminescent cloud which appeared near the end of an aurora streamer. The apparatus, which has been described olsewhere ${ }^{1,2}$, was in use for the study of meteoric ionization simultaneously on frequencies of $72 \mathrm{Mc} / \mathrm{s}$. and $46 \mathrm{Mc} . \mathrm{s}$. At Aug. 16d.00h. 10m. U.T., an echo was observed intermittently on the $46 \mathrm{Mc} / \mathrm{s}$. equipment at a range of $480 \mathrm{~km}$. By $00 \mathrm{~h}$. $20 \mathrm{~m}$. the amplitude had increased to three times the normal noise-level. It then decreased with slow fluctuations in intensity, and after twenty minutes was lost in the noise-level at $00 \mathrm{~h} .30 \mathrm{~m}$. U.T. A second echo appeared at $460 \mathrm{~km}$. range at $00 \mathrm{~h}$. $25 \mathrm{~m}$. U.T. and lasted for four minutes. Also at $00 \mathrm{~h}$. $10 \mathrm{~m}$. U.T., an increase in noise-level was apparent on both 72 and $46 \mathrm{Mc} / \mathrm{s}$. equipments over the range $450-600 \mathrm{~km}$. The noise increase persisted and increased in range to $700 \mathrm{~km}$. by $00 \mathrm{~h} .35 \mathrm{~m}$. б.т., when it disappeared. Simultaneously with the appearance of the echoes, a faint bluegrey auroral cloud appeared near the zenith at the upper tip of one of the streamers, which were at that time covering the whole of the northern sky. The streamers receded from the zenith but the cloud grew in intensity, and at $00 \mathrm{~h}$. $35 \mathrm{~m}$. U.T. broke into nine striations and rapidly faded. The radio echoes thus vanished when the cloud became striated. The entire aurora was visible from darkness on Augusit 15d. to August 16d. 02h. $30 \mathrm{~m}$. U.T., but apart from the effects recorded above no other unusual echoes were observed.

It may be assumed that this auroral cloud gave rise to an ionospheric type of radio echo rather than the scattering from a line source which is charaateristic of the transient meteoric echoes. In this case the intensity of the ionization may be estimated, since the echoes were visible on the $46 \mathrm{Mc}$./s. equipment but not on $72 \mathrm{Mc} / \mathrm{s}$. The critical frequency, therefore, lies within this frequency range. Applying the usual formula for the critical frequency ${ }^{3}$ :

$$
N=1 \cdot 24 \times 10^{-8} f^{2},
$$

where $N$ is electron density/c.c. and $f$ is ordinary ray critical frequency in c./s., we obtain an ionization density in the range

$$
2 \cdot 6 \times 10^{7}-6.5 \times 10^{7} \text { electrons/c.c. }
$$

This is about a hundred times greater than the normal ionization density in the $F$-region during the night.

The cause of the general noise increase from 450 to $700 \mathrm{~km}$. observed on both frequencies may be due to the reflexion of the transmitted signal from a large number of subsidiary seattering points associated with the main cloud.

Since the auroral cloud was visible near the zenith, the mensured range of $480 \mathrm{~km}$. may be assumed to be the height of the cloud above the earth's surface. 'This height falls well within the range of aurora heights measured by Störmer from visible observations during the years $1911-44^{4}$.

This appears to be the first record of reflexions from aurora on frequencies well above tho critical $E$ - and $F$-layor froquencies. It seems possible, however, that some of the sporadic $E$-layer effects found by workers in polar regions ${ }^{5,6}$ may be cases of direct reflexion from the aurora forming in the $100 \mathrm{~km}$. region.

These observations were made at the Jodrell Bank Experimental Station of the University of Manchester ; lat. $53^{\circ} 13^{\prime} 53^{\prime \prime} \mathrm{N}$., long. $2^{\circ} 18^{\prime} 11^{\prime \prime} \mathrm{W}$.
A. C. B. LOVELL
J. A. Chegat
C. D. EliyetT

Physical Laboratories,

University,

Manchester.

Aug. 31 .

${ }^{1}$ Prentice, Lovell and Banwcll, Mon. Not. Roy. Ast. Soc., in the press ' Lovell, Banwell and Clegg, Mon. Not. Roy. Ast. Soc., in the press ; sce also Nature, 159, 119 (1947) and 180, 75 (1947).

${ }^{3}$ Appleton and Builder, Proc. Phys. Soc., 45, 208 (1933).

4 Störmer, T'err. Mag. and Atmos. Elect., 501 (Dec. 1946).

s For example, Appleton, Naismith and Tngram, Phil. Trans., 236, 191 (1937).

${ }^{6}$ Pierce, Phys. Rev., 71, 88 (1947). 